Research Article

\title{
Intertillage during Natural Farming Rice Paddy Production Negatively Impacted the Microbial Abundances in Soils but Not Diversities
}

\author{
Jin-Feng Lin $\mathbb{D}^{1},{ }^{1}$ Eva-Maria Minarsch $\mathbb{D}^{2},{ }^{2}$ Munehide Ishiguro, ${ }^{3}$ and Yoshitaka Uchida $\mathbb{D}^{3}$ \\ ${ }^{1}$ Graduate School of Agriculture, The Special Postgraduate Program in Biosphere Sustainability Science, Hokkaido University, \\ Sapporo 060-0808, Japan \\ ${ }^{2}$ Justus-Liebig-University Gießen, Chair of Organic Farming, Karl-Glöckner-Strabe 21 C, 35394 Gieben, Germany \\ ${ }^{3}$ Research Faculty of Agriculture, Hokkaido University, Sapporo 060-0808, Japan
}

Correspondence should be addressed to Jin-Feng Lin; m9251014@gms.ndhu.edu.tw

Received 20 October 2020; Revised 22 January 2021; Accepted 25 January 2021; Published 3 February 2021

Academic Editor: Maman Turjaman

Copyright (C) 2021 Jin-Feng Lin et al. This is an open access article distributed under the Creative Commons Attribution License, which permits unrestricted use, distribution, and reproduction in any medium, provided the original work is properly cited.

In natural farming rice paddies, intertillage (tillage between rows, during rice growth period) is often performed mainly to remove weeds without the use of chemicals. Also, the intertillage disturbs soil surfaces, potentially impacting the characteristics of soil microbial communities, such as their diversity and abundance. Natural farming systems aim to maintain biodiversity, but it remains unclear whether the intertillage impacts soil microbes in rice paddies. Thus, this study aimed to understand to what extent "five times intertillage" treatment (5T) influences soil bacterial abundance and community structures compared with no tillage $(\mathrm{NT})$, under a natural farming rice paddy system. Soils were sampled at rice proximity, soil surface, and $10 \mathrm{~cm}$ depth in a natural farming rice paddy, during the early to late vegetative phase (June to July), in Hokkaido, Japan. The 16S rRNA community structures and abundance were analyzed by next generation sequencing (NGS) and quantitative PCR, respectively. We observed that NT had significantly higher bacterial abundances at the soil surface than 5T. However, there were no clear differences between 5T and NT, regarding the bacterial community structures, including their diversity indices. Instead, the sampling timings markedly impacted the bacterial community structures for the rice proximity and soil surface, showing increasing diversity indices at the late vegetative stage, compared to the early vegetative stage, suggesting the interaction between the crop growth and bacterial communities. In this study, we did not observe the significant difference between the rice yield from NT $\left(2.3 \pm 0.7 \mathrm{t} \cdot \mathrm{ha}^{-1}\right)$ and $5 \mathrm{~T}$ plots $\left(2.7 \pm 0.9 \mathrm{t} \cdot \mathrm{ha}^{-1}\right)$; however, the $5 \mathrm{~T}$ might have negatively impacted soil bacterial abundances but not the community structure of the bacteria.

\section{Introduction}

Natural farming is an alternative agricultural system to grow food, which is highly supported by microbial functions rather than utilization of various types of fertilizer [1-4]. The concept of natural farming is similar to conservation agriculture (often involves minimal tillage or no tillage (NT) and rotation) [5-7], yet differs from organic farming (still in need of plowing, tilting, spreading organic fertilizer, and weeding).

Regarding natural farming rice paddy systems, Kasubuchi et al. [8] concluded that conducting five times inter tillage (5T) in a natural farming rice paddy during the rice growing period can increase the yield as high as that of the conventional farming about five years later. Multiple intertillage methods had been widely conducted in rice paddies to control weed growth during Edo period which was from the end of $17^{\text {th }}-18^{\text {th }}$ century. Intertillage is performed during the rice growth period, using a small machine with chainweeder to control weeds amounts (Supplementary Photo 1), enhance soil aeration, plant root growth, and water infiltration [8].

Generally, tillage can soften soil for plant root to spread over a deeper distance underneath the soil surface; shatter 
soil organic matter to accelerate the release of nutrients for crop growth; remove weed to minimize its competition with crop; incorporate oxygen which benefits aerobic microorganisms active [9-12]. Contrastingly, tillage decreases microbial abundance and activities in a long-term period due to increasing decomposition rate of soil organic matter which contains dead animal body and plant $[13,14]$. In contrast to tillage treatment, NT treatment can increase formation of soil organic matter and soil aggregate because there is no disturbance on soil, thus further improving soil microbial activities [15-19].

However, the difference in microbial abundance and diversity under NT and intertillage treated soils in naturally managed rice paddy systems was not well understood. The intertillage is performed during the rice growth period, when the field is submerged in water; thus the impact of the tillage in the rice paddy can be different from the impact of tillage for the upland soils. Therefore, better understanding of the impacts of intertillage on soil microbial abundance and diversity, specific for the natural farming rice paddy, is required to elucidate the reasons behind the successfulness of this system. The maintenance of soil microbial activities and functions is critically important for natural farming, in general.

Thus, the primary goals of this study were to compare the dissimilarity of soil bacterial abundance and diversity under 5T and NT treatment within a paddy farm managed using the natural farming style. We hypothesized the following: (1) soil bacterial abundance and community would sharply change after intertillage compared with NT; (2) 5T and NT treatment would be significantly at variance with soil bacterial abundance and community for the duration of vegetative phase.

\section{Materials and Methods}

2.1. Field Sites and Agricultural Management. The study was conducted on flooded rice paddy research fields of the Field Science Centre of Hokkaido University, Sapporo, Japan $\left(\mathrm{N} 43^{\circ} 04^{\prime} 39^{\prime \prime} \mathrm{N} / \mathrm{E} 141^{\circ} 20^{\prime} 03^{\prime \prime} \mathrm{E}\right)$ (Supplementary Figure S1). The trial investigates the dynamic of intertillage and NT treatments in a natural farming rice paddy. In this study, we focused on 5T and NT treated plots. The natural managed paddy is $40 \times 25 \mathrm{~m}$ in size and divided in nine plots with $13.34 \times 8.33 \mathrm{~m}$ in size each. The natural farming rice paddy alongside with no fertilizer, herbicide, pesticide, and insecticide application was established in 2017. Before 2017, there were three years maintained by flooded conditions during the cropping seasons with no crop growth and herbicide application. Also, the fields were ploughed at one month before seedlings were transplanted to the paddy fields. The treatment of the nine plots is divided in 0,2 , and 5 times intertillage (three plots each) (Supplementary Figure S2).

2.2. Soil Sampling Procedure. In frame of the study, plots from the natural farming rice paddy with $5 \mathrm{~T}$ and NT treatment were sampled. To investigate short-term effects of
5T treatment compared with NT, samples were taken one day before and two days after management activities for the third, fourth, and fifth intertillage event. The third and fifth intertillage events corresponded to early vegetative phase (June) and late vegetative phase (July), respectively. In total, six plots were sampled corresponding to three replicates per treatment. From each plot, soil samples were taken at three different locations within a square of two rows of five consecutive rice plants. The soil surface samples were taken from soil layer at $0-0.5 \mathrm{~cm}$ depth, between plant rows. The rice proximity samples were taken from the rhizosphere zone of the rice plants. A spatula was used to scrape off the soil attached to the rice roots. The rice roots were exposed at the soil surface (in the paddy water) thus the scraping could be performed easily. The $10 \mathrm{~cm}$ samples were taken from between the rice plant rows, similar to the soil surface samples, but at $9-11 \mathrm{~cm}$ depth. At $10 \mathrm{~cm}$ depth, the soils were not disturbed by the intertillage (Supplementary Figure S3).

2.3. $16 S$ Sequencing Library Preparation. The DNA of the sampled soils was extracted using a NucleoSpin Soil Kit (Macherey-Nagel GmbH \& Co. KG, Düren, Germany) according to the manufacturer's protocol, and buffer SL2 was used. A negative extraction control was performed using empty extraction tubes with the first and last extraction. The DNA extract was quantified using Qubit 2.0 Fluorometer (Invitrogen, Waltham, United States) and a Qubit dsDNA BR Assay Kit. The V4 region of the 16S rRNA gene was amplified using PCR primer F515 (5'-CACGGT CGKCGGCGCCATT- $\left.3^{\prime}\right)$ and R806 (5'-GGACTAC HVGGGTWTCTAAT- $3^{\prime}$ ). An AmpliTaq Gold ${ }^{\circledR} 360$ Master Mix (Applied Biosystems ${ }^{\mathrm{TM}}$, Carlsbad, USA) and $5 \mathrm{ng}$ input DNA were used for the PCR. The PCR program included initial denaturation at $95^{\circ} \mathrm{C}$ for $10 \mathrm{~min}$ followed by 20 cycles of denaturation at $95^{\circ} \mathrm{C}$ for $30 \mathrm{sec}$, annealing at $57^{\circ} \mathrm{C}$ for $30 \mathrm{sec}$, and elongation at $72^{\circ} \mathrm{C}$ for $1 \mathrm{~min}$ and ended with final elongation at $72^{\circ} \mathrm{C}$ for $7 \mathrm{~min}$. A positive control using E. coli DNA control (Applied Biosystems ${ }^{\mathrm{TM}}$, Carlsbad, USA) and a negative control were performed with the same conditions. The amplicons were checked on a $1.5 \%$ agarose gel. Purification of PCR products was performed using an Agencourt AMPure XP kit (Beckman Coulter Inc., Webster, United States) according to the manufacturer's protocol. Ten nanograms of amplified DNA per sample was barcoded using the IonA-barcode[i]-F515 forward and IonP1-R806 reverse primers. The PCR program included the same conditions like above but with 5 cycles. The barcoded amplicons were purified and quantity-checked as described above. The quality was analyzed on an Agilent 2100 Bioanalyzer (Agilent Technologies, Inc., Santa Clara, USA) using an Agilent DNA 1000 Kit. The library was diluted to 50 pM and loaded into the Ion 314 Chip (Thermo Fisher Scientific K.K., Japan) using the Ion Chef Instruments (Thermo Fisher Scientific K.K., Japan) with the Ion PGM ${ }^{\mathrm{TM}}$ Hi-Q Chef Kit. DNA sequencing was conducted on the Ion PGM Sequencer (Thermo Fisher Scientific K.K., Japan) using the Ion PGM 400 Kit. 
2.4. Gene Abundance Assay. Abundance of the $16 \mathrm{~S}$ rRNA gene was assessed by quantitative polymerase chain reaction (qPCR) using a Stratagene Mx3005P cycler (Agilent Technologies, Inc., Santa Clara, USA). Prior to the experiment, the qPCR assay was optimized using different oligonucleotide concentrations, soil dilutions, and annealing temperatures to reach $R^{2}>0.999$ and amplification efficiencies (Eff) between 0.8 and 1. The amplification efficiencies were calculated using the following formula: $\mathrm{Eff}=10^{(-1 / \text { slope })}-1$. The qPCR reactions were performed in $20 \mu \mathrm{l}$ using KAPA SYBR green Master Mix (Takara Bio) and $400 \mathrm{nM}$ of each primer F515 and R806. The cycler program was set with an initial enzyme activation step for $5 \mathrm{~min}$ at $95^{\circ} \mathrm{C}$ and annealing step for $1 \mathrm{~min}$ at $58^{\circ} \mathrm{C}$. The DNA extracts were 100 -fold diluted. The biological replicates were analyzed in technical duplicates. Negative controls and serial dilutions of amplified E. coli DNA $\left(10^{2}\right.$ to $\left.10^{6} \mathrm{ng} / \mu \mathrm{l}\right)$ were included in every qPCR run to calculate standard curves for absolute quantification. Melting curve analyses were performed to check the quality of the generated amplicons.

2.5. Measurement of Ammonium and $p H$. The determination of the inorganic- $\mathrm{N}$ concentrations was performed following the approaches taken by Silva and Hatton and Pickering $[20,21]$. Firstly, $2 \mathrm{~g}$ of the sampled fresh soil was extracted with $2 \mathrm{M} \mathrm{KCl}(10 \mathrm{ml})$. After shaking the mixture for $60 \mathrm{~min}$, the suspension was filtered through a filter paper (Grade 5C, $<5 \mathrm{~mm}$; Advantec, Tokyo, Japan). The extracted solution was stored at minus $20^{\circ} \mathrm{C}$ until measurement. For the measurement, a colorimetric method was employed with a flow injection analyzer (AQLA-700; Aqualab, Tokyo, Japan) $[22,23]$. To measure soil $\mathrm{pH}, 5 \mathrm{~g}$ of fresh soil was shaken with $25 \mathrm{ml}$ of $10 \% \mathrm{KCl}$ for 30 minutes. The $\mathrm{pH}$ of the extracts was measured by $\mathrm{pH}$ meter (AS800, AS ONE Corporation, Osaka, Japan).

2.6. Analysis of the $16 S$ rRNA-Based Bacterial Community Structures. The barcoded 16S rRNA gene sequences were demultiplexed, quality-filtered, and assessed using the Quantitative Insights Into Microbial Ecology (QIIME) workflow [24]. The next generation sequencing based method showed the loading density was at $87 \%$ and $94 \%$. On average, 58,889 reads were mapped per $16 \mathrm{~S}$ rRNA sample. Operational Taxonomic Units (OTUs) were prepared by eliminating all the OTUs that matched the GreenGenes 13_5 reference sequence with $97 \%$ similarity. To analyze the changes in microbial community and their interactions with other environmental factors, Principal Component Analysis (PCA) was performed; the PCA plots were separated into three parts with same variation. Soil microbial community analysis was performed with permutational multivariate analysis of variance (PERMANOVA) and the Bray-Curtis distance based on 999 permutations of the raw data using the Adonis function in $R$.

2.7. Statistical Analysis. For the $\mathrm{pH}$ and concentration of ammonium, two-way and three-way analysis of variance
(ANOVA) were performed to investigate the effect of the location and the duration. One-way ANOVA and Tukey-Kramer multiple comparison tests were performed for the analysis of significant differences among samples on duration or for each treatment. Statistical analyses were performed by $R$ 3.6.1 [25] and we set the significance level at $P<0.05$.

\section{Result}

3.1. Bacterial Abundance. At the soil surface, the bacterial abundance in the NT soils was higher than that in the 5T soils $(P<0.05)$; however, the abundances of bacteria in soils were similar between NT and $5 \mathrm{~T}$ at the rice proximity and $10 \mathrm{~cm}$ depth (Figure 1). The bacterial abundance was higher at the rice proximity and soil surface, compared with $10 \mathrm{~cm}(P<0.05)$. The bacterial abundance was decreasing over time for the soil surface and rice proximity, but it was relatively stable over time at the $10 \mathrm{~cm}$ depth soils.

When averaged across the sampling timings, NT soils had a larger amount of DNA, when compared with $5 \mathrm{~T}$ soils, in the soil surface, but this was not observed for the rice proximity and the $10 \mathrm{~cm}$ depth soils (Figure 2). The raw soil DNA concentrations increased over time at the rice proximity and soil surface under NT treatment. For the 5T at the rice proximity and soil surface, the raw DNA concentrations peaked at day 32 and did not show increase towards the later stage of the experiment. At the $10 \mathrm{~cm}$ depth, the raw DNA concentrations under NT and 5T treatment had the similar fluctuation and they were lower than the other locations.

3.2. Bacterial Community. On early vegetative phase, the bacterial community structure was similar at the same location regardless of the tillage treatment (Figure 3). However, there was a significant difference between $10 \mathrm{~cm}$ depth and rice proximity as well as soil surface (Supplementary Table S1). At the rice proximity location, NT treatment had a higher bacterial relative abundance in Chloroflexi (9.91\%), Gemmatimonadetes (6.07\%), and Spirochaetes (10.66\%) compared to the 5T, while Acidobacteria (8.33\%) and Betaproteobacteria $(8.63 \%)$ were relatively higher in the $5 \mathrm{~T}$ compared to the NT treatment. At soil surface location, NT treatment had a higher Spirochaetes $(10.11 \%)$ bacterial abundance, but Chloroflexi (12.26\%) had a higher relative abundance under $5 \mathrm{~T}$ treatment, compared to the NT. At $10 \mathrm{~cm}$ depth location, Firmicutes (17.71\%) was higher under NT treatment, but Planctomycetes (3.37\%) and Spirochaetes (9.55\%) were higher under $5 \mathrm{~T}$ treatment, compared to the NT. The $\mathrm{N}_{2}$-fixing genus only appeared at the rice proximity and soil surface, while the relative abundances of Firmicutes and Archaea predominated $10 \mathrm{~cm}$ depth location. Nonetheless, there were no specific bacteria predominating rice proximity and soil surface locations.

On late vegetative phase, the bacterial community structure (Figure 3) was alike among three locations. There were no bacteria particularly predominating rice proximity, soil surface, and $10 \mathrm{~cm}$ depth locations. Nevertheless, we observed that several bacterial clusters partly fluctuated from 


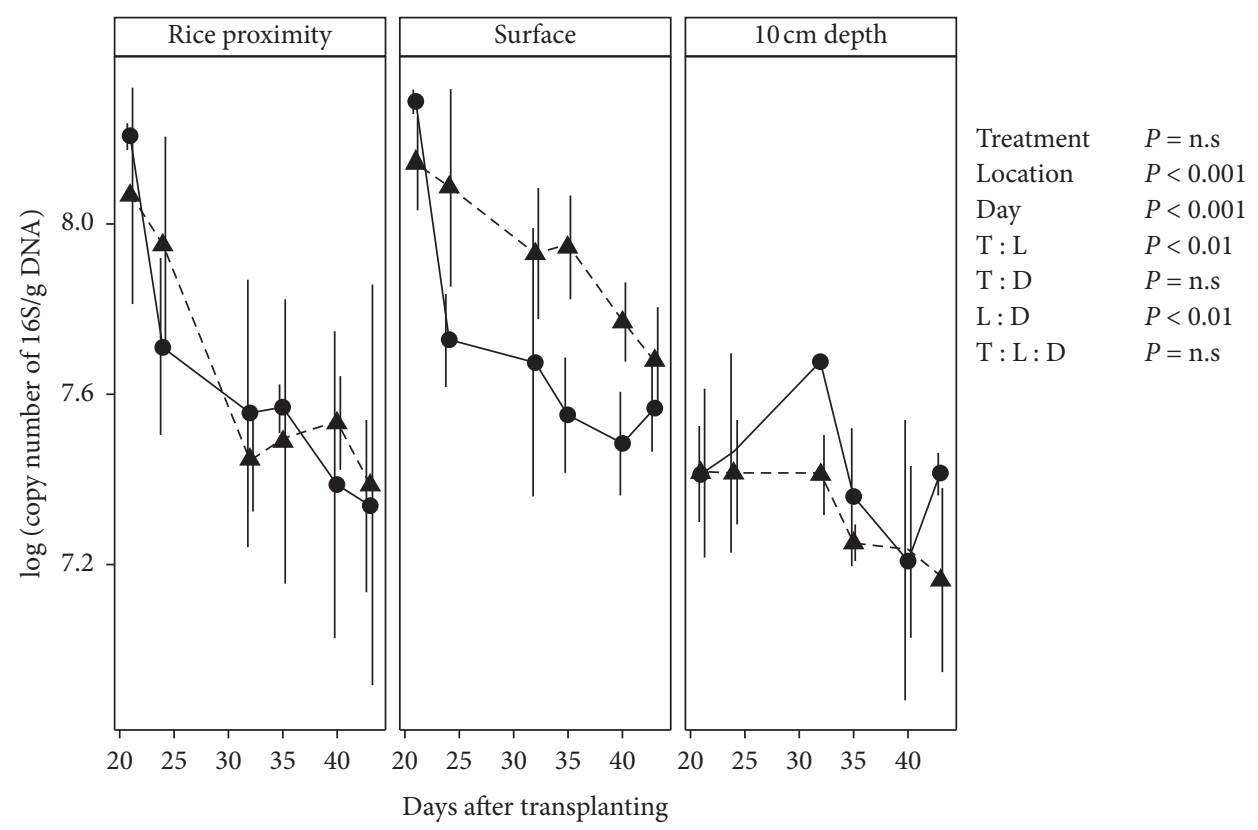

Treatment

$\rightarrow 5 \mathrm{~T}$

$-\boldsymbol{\Delta}-\mathrm{NT}$

FIgURE 1: The time course changes of $16 \mathrm{~S}$ bacterial abundance under no tillage (NT) and 5 times tillage (5T) at three different locations (rice proximity, surface, and $10 \mathrm{~cm}$ depth) after transplanting. Level of significance was determined by and two-way ANOVA. Error bars indicate standard deviations $(n=3)$.

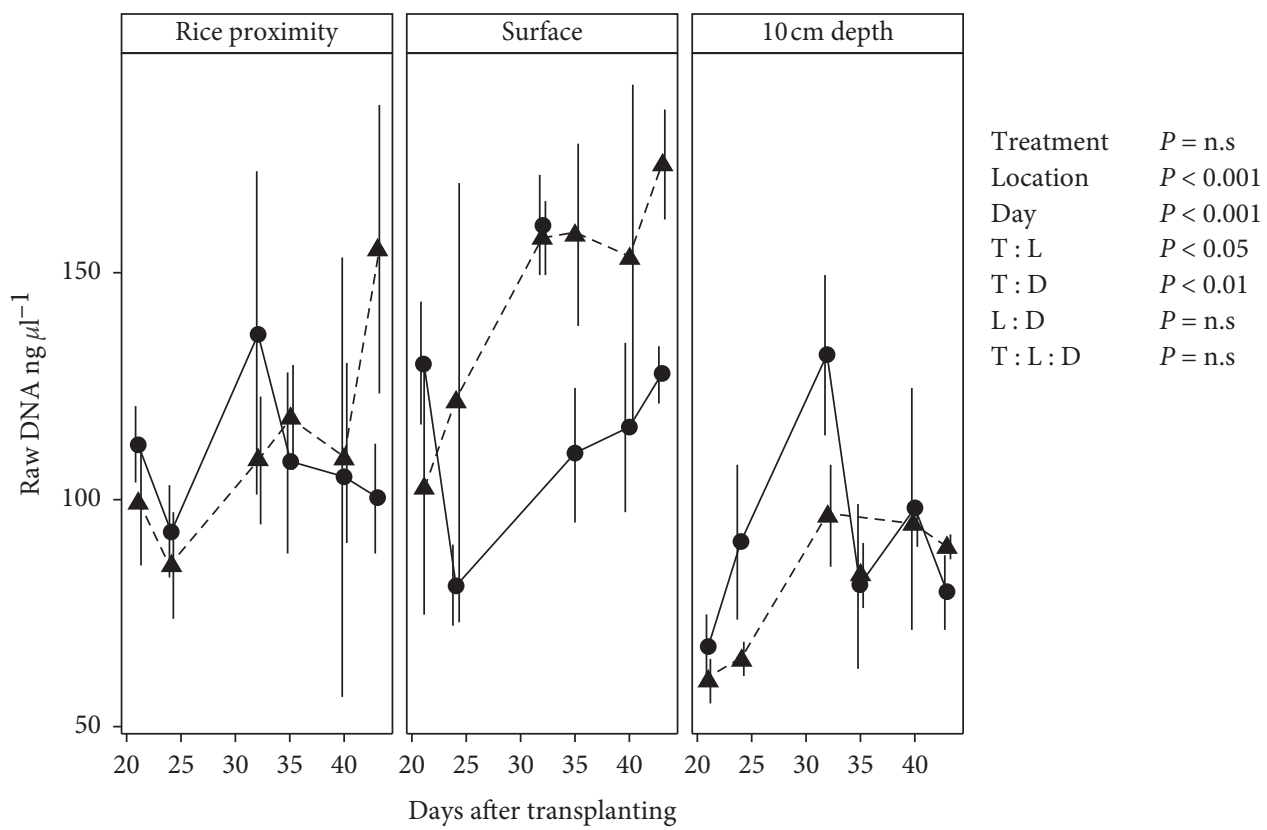

Treatment

$-5 \mathrm{~T}$

$-\mathbf{-}-\mathrm{NT}$

Figure 2: The time course changes of raw DNA under no tillage (NT) and 5 times tillage (5T) at three different locations (rice proximity, surface, and $10 \mathrm{~cm}$ depth) after transplanting. Level of significance was determined by two-way ANOVA. Error bars indicate standard deviations $(n=3)$. 

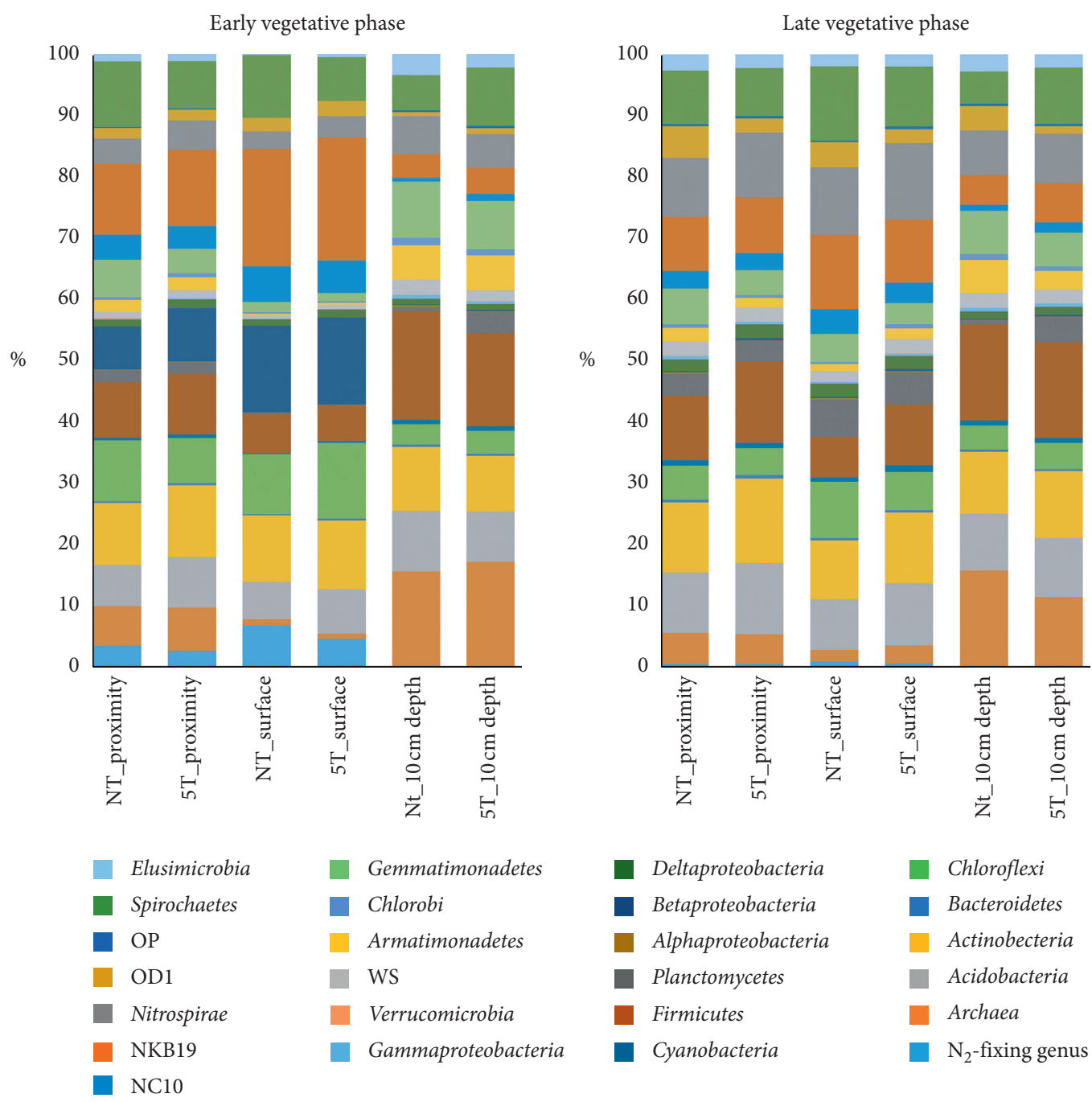

Figure 3: Relative abundances for the bacterial community under no tillage (NT) and 5 times tillage (5T) treatment in three different locations (rice proximity, surface, and $10 \mathrm{~cm}$ depth) at early vegetative phase and late vegetative phase. Proteobacteria were shown in class level; " $\mathrm{N}_{2}$ fixing genus" included Pseudomonas, Azoarcus, Rhizobium, Anabaena, Azospirillum, and Bradyrhizobium. Other bacteria were shown in phyla level.

the early vegetative phase to the late vegetative phase. The relative abundance of Deltaproteobacteria Geobacter increased obviously at the rice proximity and soil surface. Contrastingly, Betaproteobacteria, Firmicutes, and Pseudomonas had decreased at the two locations. The $10 \mathrm{~cm}$ depth was a relatively steady location compared to the rice proximity and soil surface.

The result of PERMANOVA showed soil bacterial community structure was significantly influenced by vegetative phase $(\mathrm{p}<0.001)$ rather than treatment (Supplementary Table S1). The Shannon diversity index was also significantly influenced by the vegetative phase $(P<0.001)$ (Supplementary Table S2). Its result showed that the bacterial diversity in the rice proximity and the soil surface increased over time, but it was maintained at the $10 \mathrm{~cm}$ (Supplementary Table S3).

Based on the PCA, there were no clear clusters of NT and 5T (Figure 4(a)), suggesting there were no major impacts of the intertillage on the bacterial community structures. For the locations of rice proximity and soil surface, they clustered differently by the two vegetative phases (Figure 4(b)). In contrast to the rice proximity and soil surface locations, the $10 \mathrm{~cm}$ depth data made a separate cluster on the PCA, and the NT and 5T showed different clusters for the $10 \mathrm{~cm}$ depth.

The PCA on genus level (Figure 4(c)) indicated that genus Clostridium predominated the rice proximity and surface under both treatments on early vegetative phase. Stramenopiles (or Heterokonts), a microeukaryotic community whose most were algae [26], predominated rice proximity and surface under both treatments on late vegetative phase. With regard to $10 \mathrm{~cm}$ depth location, the uncultured order pGrfC26 of the Miscellaneous Crenarchaeota Group (MCG) was predominant.

3.3. Dynamics of $p H$ and Ammonium. When averaged across the rice vegetative phase, soil $\mathrm{pH}$ was the highest on the soil surface $(6.8 \pm 0.01)$, followed by the rice proximity 

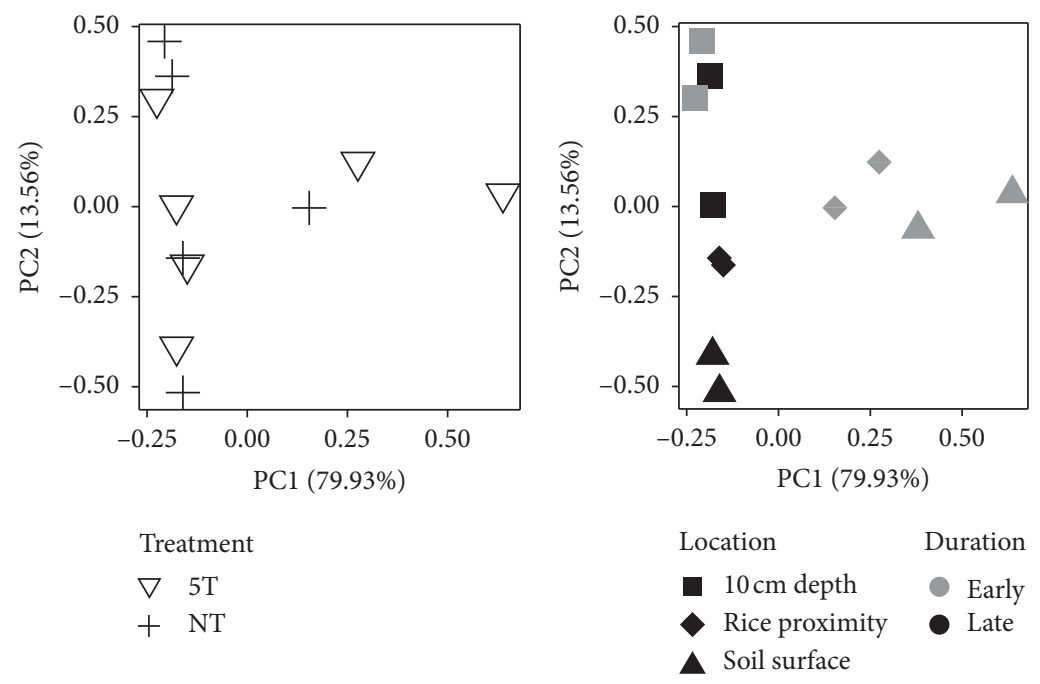

(a)

(b)

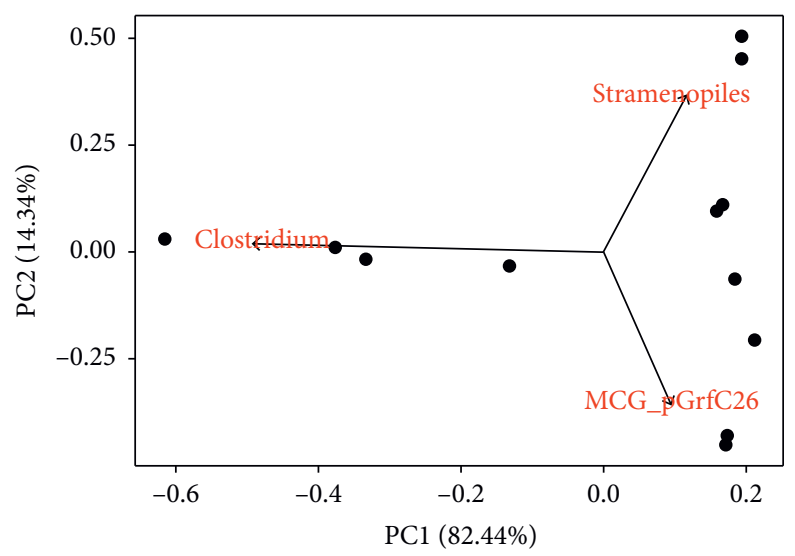

(c)

Figure 4: Principal component analysis (PCA) on (a) treatment with no tillage (NT, cross) and 5 times tillage (5T, triangle) and (b) interaction between duration (early vegetative phase (gray) and late vegetative phase (black)) and location (rice proximity, soil surface, and $10 \mathrm{~cm}$ depth). (c) Arrows show bacteria on genus level. Axes 1 and 2 account for 72 and $16 \%$ of the variation, respectively.

$(6.5 \pm 0.02)$ and the $10 \mathrm{~cm}$ depth $(6.2 \pm 0.02)$. Soil $\mathrm{pH}$ decreased from 21 days to 43 days under NT and 5T treatment at both rice proximity and soil surface location. The $\mathrm{pH}$ of rice proximity and soil surface under NT and 5T treatment decreased about $5 \%$. Soil $\mathrm{pH}$ at $10 \mathrm{~cm}$ depth location under NT and 5T treatment was relatively stable, ranging from 6.25 to 6.08. There was a significant difference between location and duration $(P<0.001)$ (Figure 5). However, soil $\mathrm{pH}$ whether disturbed (5T) or not (NT) did not show obvious significant discrepancy.

The ammonium declined from 21st day at the early growth after transplanting at the rice proximity and soil surface (Figure 6). There was a significant difference between days $(P<0.001)$, but there was no significant impact on the tillage treatments. The amount of ammonium concentration declined at rice proximity (23 to $9 \mathrm{mg} \cdot \mathrm{kg}^{-1}, \mathrm{NT} ; 19$ to $7 \mathrm{mg} \cdot \mathrm{kg}^{-1}, 5 \mathrm{~T}$ ) and soil surface ( 25 to $11 \mathrm{mg} \cdot \mathrm{kg}^{-1}, \mathrm{NT} ; 21$ to $9 \mathrm{mg} \cdot \mathrm{kg}^{-1}$, 5T) from 24 days to 32 days and afterwards slightly increased by 43 days after transplanting. There was a significant difference at the $10 \mathrm{~cm}$ depth location between
NT and 5T treatment. The ammonium concentration at the $10 \mathrm{~cm}$ depth was relatively stable compared with the rice proximity and soil surface.

\section{Discussion}

Our study found that there was a negative impact of the tillage on the bacterial abundances $(P<0.05)$ at the soil surface (Figure 1). However, the tillage treatment did not impact the bacterial abundance in soils at the rice proximity and $10 \mathrm{~cm}$ depth. We note that the rice grain yields for the 0 and 5 times intertillage treatments were $2.3 \pm 0.7$ and $2.7 \pm 0.9 \mathrm{t} \cdot \mathrm{ha}^{-1}$, respectively, without the significant difference between them. The tillage disturbs soil surfaces, and the disturbance must have negatively influenced the soil microbial abundance on the soil surfaces in our study. Previous studies also had shown that a tillage treatment results in lower microbial biomass than NT treatment at the soil surface [27, 28]. Previous studies stated that the negative impact of the tillage on soil microbial biomass was due to the 


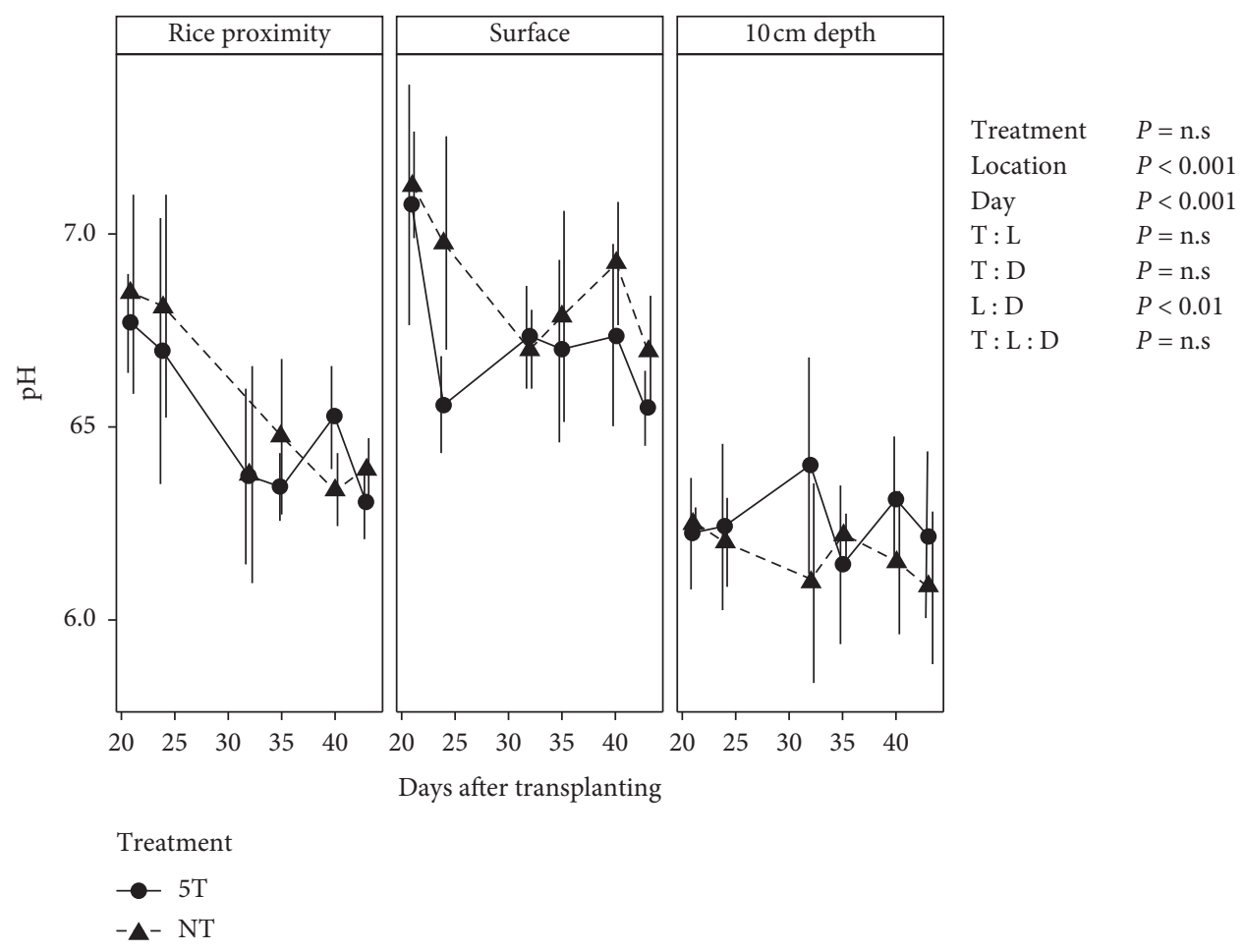

FIGURE 5: Change of soil $\mathrm{pH}$ after transplanting at location rice proximity, surface, and $10 \mathrm{~cm}$ depth under no tillage (NT) and 5 times tillage (5T) treatment. Level of significance was determined by three-way ANOVA. Error bars represent standard deviations $(n=3)$.

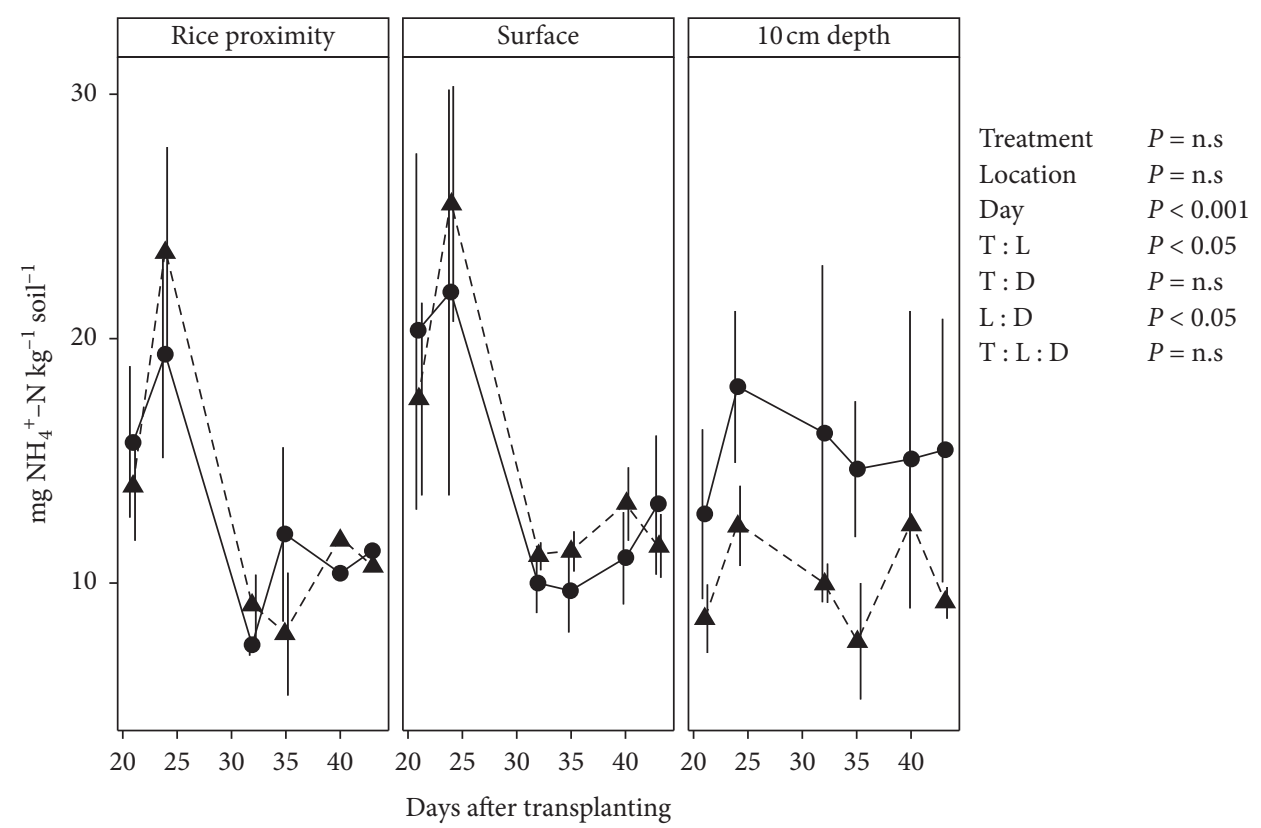
Treatment
$-5 \mathrm{~T}$
$-\boldsymbol{\Delta}-\mathrm{NT}$

FigURE 6: Fluctuation of ammonium $\left(\mathrm{NH}_{4}{ }^{+}-\mathrm{N}\right)$ after transplanting at location of rice proximity, surface, and $10 \mathrm{~cm}$ depth under no tillage (NT) and 5 times tillage (5T) treatment. Level of significance was determined by three-way ANOVA. Error bars represent standard deviations $(n=3)$. 
disruption of microbial extracellular enzyme activities. For example, one of the enzymes in soils, Beta-Glucosidase activity, is positively related to total soil carbon that is closely associated with soil microbial biomass [29-31]. In contrary to tillage, NT treatment retains the soil carbon in soils, when compared to the systems with tillage, and this allows microorganisms to grow [32]. Schmidt et al. [33] also indicated that, at a $0-5 \mathrm{~cm}$ soil depth, the NT treatment led to higher copy number of bacteria that was approximately $7.5 \times 10^{8}$ copy $\mathrm{kg}^{-1}$ soil (this study was from $4.9 \times 10^{7}$ to $1.4 \times 10^{8}$ copy $\mathrm{kg}^{-1}$ soil at the soil surface) when compared to that under the tillage treatment. However, the same study indicated that this was not the case at deeper soil layers. Thus, we conclude that the disturbance of soil microbes occurred in rice paddy soils by intertillage occurrence, even when the soils were submerged in water, similar to previous reports performed in upland soils.

Also, we found that the $16 \mathrm{~S}$ rRNA copy number at the location of rice proximity and soil surface under NT and 5T treatment decreased along with rice growth (Figure 1), but at the $10 \mathrm{~cm}$ depth it was more stable compared to other locations. This was consistent with the previous studies that $16 \mathrm{~S}$ rRNA copy number decreased with increasing plant growth [31, 34]. We also observed the highest amount of $16 \mathrm{~S}$ rRNA copy number appeared on the early vegetative phase. Thus, we assumed that one of the reasons for the decrease of bacterial abundances might be caused by rice plants rapidly consuming nutrients resulting in nutrient deficiency for microbial growth $[33,35,36]$. Therefore, the effect of intertillage on the microbial growth may depend on the nutrient availability in the soils; thus the interaction between the soil's nutrient availability and intertillage treatments should be further studied, regarding the soil microbial abundance. In the current study, we aimed to compare tillage and no tillage systems within a natural farming rice paddy. However, future studies should compare the natural farming and conventional systems, regarding the relationships between plant growth and microbial abundance, because we were uncertain whether the use of chemical fertilizers and other practices in the conventional farming systems change the relationship between plant growth and microbial abundance.

As another factor controlling the microbial abundance in the current study, the bacterial abundance peaked at around $\mathrm{pH}$ of 7 and decreased with soil $\mathrm{pH}$ at the rice proximity and soil surface both under NT and 5T treatments (Figures 1 and 5). This agreed to a previous study reporting that the bacterial growth was correlated with soil $\mathrm{pH}$ and tended to be relatively higher at around neutral soil $\mathrm{pH}$ environment [37]. However, unexpectedly, our results showed an increase of the raw DNA concentrations with decreasing soil $\mathrm{pH}$ and over the experimental period, particularly for the NT (Figure 2). Other biological activities such as fungal, faunal, or plant activities might have contributed to the increase of raw soil DNA amount; for example, previous studies reported that acidic environments promoted fungal activities, while bacterial activities decreased along with reducing soil $\mathrm{pH}[35,38]$. Also, NT systems can improve the soil porosity by increasing $0.5-50 \mathrm{~mm}$ macropores, as well as altering water holding capacity $(0-10 \mathrm{~cm})$ and the amount of exchangeable ions, compared with tillage systems [35, 38, 39]. Thus, further investigation is needed to identify the factors contributing to the increase of the raw DNA concentrations.

For the community structures of bacteria in the soils, there was no clear impact of intertillage treatments, when compared to NT (Figure 4(a)). Rather, the sampling timing influenced the community structures, particularly at soil surface and rice proximity (Figure 4(b)). For example, Clostridium of Firmicutes in rice proximity and surface was present in relatively larger amount during the early vegetative phase compared to the late vegetative phase (Figure 4(c)). Clostridium is a microorganism responsible of the rice straw decomposition in a rice paddy [40, 41]. Due to low temperatures in Hokkaido limiting the microbial decomposition ability, we often find a large amount of rice straw left beneath the soil surface in spring. Thus, ours results suggested that the activated Clostridium might decompose some of the rice straw in spring. The contribution of Clostridium to the decomposition of rice straw has to be further studied, especially in relation to their low temperature activities.

Contrastingly, Stramenopiles dominated the rice proximity and soil surface soils during the late vegetative phase (Figure 4). Stramenopiles are an assemblage of eukaryotic organism, including unicellular, such as diatoms, to large multicellular forms, such as the brown algae and oomycetes. These Microeukaryotes act as grazers which can affect microbial biomass and community as well as releasing ammonium and nitrate [42]. Thus, these microbes might play an important role in natural farming rice paddy systems, providing available nitrogen to rice plants in the later stages of their growth, although further studies are needed to confirm this.

In the $10 \mathrm{~cm}$ depth soils, class MCG of Crenarchaeota showed relatively larger amount, when compared to the soils sampled from other parts (Figure 4(c)). Miscellaneous Crenarchaeota Group (MCG) of Archaea are widely distributed in terrestrial and marine ecosystem [43]. These microorganisms play an important role in biogeochemical cycles. MCG in anaerobic soil ecosystem are related to degrade carbon from plant, reduce nitrite to ammonium, and produce acetate [44]. Undecomposed rice straw, which was found while soil sampling at the $10 \mathrm{~cm}$ depth under both treatments, possibly led MCG to be in the majority as well as lower $\mathrm{pH}$ and higher ammonium concentration compared to the rice proximity and soil surface.

Overall diversities of the bacterial communities also did not show the difference between the tillage treatments (Supplementary Table S2). However, the rice proximity and soil surface under NT and 5T treatment showed a significant increase of microbial diversity on late vegetative phase, compared to the $10 \mathrm{~cm}$ soils (Supplementary Table S3). There were previous studies [45-47] that found that NT treatments increased microbial community's diversity when compared to the soils under tillage, but other previous studies concluded that the NT treatment did not influence the microbial community $[48,49]$. The microbial diversities' 
fluctuations over the growing period might have been the reasons behind these contrasting results because microbes are influenced by fluctuating soil chemical properties such as $\mathrm{pH}$ and nutrients [50].

We expected different soil $\mathrm{pH}$ and nutrient characteristics at soil surfaces and near rice plants between the NT and $5 \mathrm{~T}$ treatments because previous studies stated that, in natural farming rice paddy systems, intertillage can incorporate oxygen to aerate soil, therefore promoting microorganism activities to decompose organic matter and crop residues, facilitating nitrogen mineralization and ammonification $[8,9,11,51]$. For the ammonium concentrations, we observed relatively higher ammonium concentration in $5 \mathrm{~T}$ than NT only in a deeper soil layer $(P<0.01)$. Possibly, the rapid consumption of ammonium ion by rice plants masked the differences between the NT and 5T, regarding the soils' chemical characteristics. In results, we observed the decrease in soil $\mathrm{pH}$ and ammonium in both of the tillage treatments and we conclude that the increase in the diversity indices with time might have been caused by increased relative abundances of acid preference bacteria, such as Acidobacteria and Firmicutes [52]. We note that our natural farming rice paddy experiment was only conducted for one year; thus the significant impact of the five times intertillage treatments (compared to NT) on soils' microbial diversity might appear more in a longer term, although it needs to be confirmed.

\section{Conclusion}

From this study, we draw the following conclusions:

(i) Bacterial abundance was higher at soil surface with no tillage, compared to the soils under intertillage. Soil surface was the most disturbed location due to the tillage; thus we observed the significant decrease in bacterial abundance in this zone, when the tillage was conducted.

(ii) Bacterial abundance was reduced over time, regardless of the tillage treatments, at rice proximity and soil surface. Decreasing nutrients and $\mathrm{pH}$ because of the plants' nutrient absorbance limited the bacterial growth and therefore led to bacterial abundance reduction.

(iii) The bacterial diversity and community structure were affected by soil $\mathrm{pH}$ which was decreasing with ammonium levels in soil. However, the impacts of the tillage treatments were not clear.

\section{Data Availability}

The raw and analyzed data used to support this study are available from the corresponding author upon request.

\section{Conflicts of Interest}

The authors declare that there are no conflicts of interest or personal relationships that could have influenced the work reported in this paper.

\section{Acknowledgments}

This study has received grants from the JSPS KAKENHI 443 Grants-in-Aid for Scientific Research (Grant number: JP 18H03963). The authors thank the laboratory members for helping them with sampling and lab works.

\section{Supplementary Materials}

Supplementary photo 1 : the intertillage machine used to remove weed in five times intertillage plots. Figure S1: the sampling site: The Field Science Centre of Hokkaido Uni-

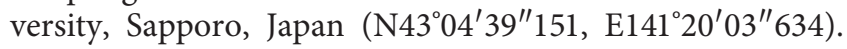
Figure S2: the experimental site of natural farming rice paddy. It was divided into nine plots and $\mathrm{A}, \mathrm{B}$, and $\mathrm{C}$ blocks. Panels were set within block (brown) and between blocks (blue). Each plot was separated with polycarbonate board. Each block includes 0 (no tillage; NT), 2 (2 times intertillage; $2 \mathrm{~T}$ ), and 5 (5 times intertillage; $5 \mathrm{~T}$ ) treatments, where soils were sampled at NT and 5T plots. Each treatment had three replicates. Figure S3: soil samples were taken from (1) rice proximity; (2) soil surface; (3) $10 \mathrm{~cm}$ depth one day before and two days after management activities for the third, fourth, and fifth intertillage event in 5T and NT plots. Table S1: PERMANOVA (Permutational multivariate analysis of variance) tested effect results of vegetative phase, location, and treatment on bacterial community composition. Table S2: results of ANOVA for Shannon index at the OTU level. Table S3: Shannon index at OTU level. Each score was shown as mean (SD). (Supplementary Materials)

\section{References}

[1] M. Fukuoka, The One-Straw Revolution: An Introduction to Natural Farming, Shunjusha Publishing Company, Tokyo, Japan, 1975.

[2] K. Hirano, M. Hayatsu, I. Nioh et al., "Comparison of nitrogen-fixing bacterial flora of rice rhizosphere in the fields treated long-term with agrochemicals and non-agrochemicals," Microbes and Environments, vol. 16, no. 3, pp. 155-160, 2001.

[3] H. L. Xu, Nature Farming in Japan, Research Signpost, Trivandrum, India, 2006.

[4] J. Liao, Q. Xu, H. Xu, and D. Huang, "Natural farming improves soil quality and alters microbial diversity in a cabbage field in Japan," Sustainability, vol. 11, no. 11, p. 3131, 2019.

[5] C. M. Pittelkow, X. Liang, B. A. Linquist et al., "Productivity limits and potentials of the principles of conservation agriculture," Nature, vol. 517, no. 7534, pp. 365-368, 2015.

[6] P.-F. Hou, C.-H. Chien, Y.-F. Chiang-Hsieh et al., "Paddyupland rotation for sustainable agriculture with regards to diverse soil microbial community," Scientific Reports, vol. 8, no. 1, 2018.

[7] FAO, "Conservation Agriculture," 2020, http://www.fao.org/ conservation-agriculture/en/.

[8] T. Kasubuchi, H. Arao, and H. Yasuda, "Warning for modem agriculture depending on chemical fertilizers and agricultural chemicals-significance of the multiple-inter-tillage-weeding method developed in Edo-era," Journal of the Japanese Society of Soil Physics, vol. 141, pp. 65-69, 2019.

[9] P. R. Hobbs, K. Sayre, and R. Gupta, "The role of conservation agriculture in sustainable agriculture," Philosophical 
Transactions of the Royal Society B: Biological Sciences, vol. 363, no. 1491, pp. 543-555, 2008.

[10] D. S. Powlson, A. Bhogal, B. J. Chambers et al., "The potential to increase soil carbon stocks through reduced tillage or organic material additions in England and Wales: a case study," Agriculture, Ecosystems \& Environment, vol. 146, no. 1, pp. 23-33, 2012.

[11] S. Fujiwara, Shinpan Zukai Dojouno Kisochishiki, Rural Culture Association, Tokyo, Japan, 2013.

[12] A. Das, R. Lal, D. P. Patel et al., "Effects of tillage and biomass on soil quality and productivity of lowland rice cultivation by small scale farmers in North Eastern India," Soil and Tillage Research, vol. 143, pp. 50-58, 2014.

[13] K. Mohammadi, G. Heidari, S. Khalesro et al., "Soil management, microorganisms and organic matter interactions: a review," African Journal of Biotechnology, vol. 10, no. 86, pp. 19840-19849, 2011.

[14] J. M. Rey Benayas and J. M. Bullock, "Restoration of biodiversity and ecosystem services on agricultural land," Ecosystems, vol. 15, no. 6, pp. 883-899, 2012.

[15] J. Six, E. T. Elliott, and K. Paustian, "Aggregate and soil organic matter dynamics under conventional and no-tillage systems," Soil Science Society of America Journal, vol. 63, no. 5, pp. 1350-1358, 1999.

[16] C. J. Baker, K. E. Saxton, W. R. Ritchie et al., No-tillage Seeding in Conservation Agriculture, $\mathrm{CAB}$ International and FAO, Rome, Italy, 2nd edition, 2007.

[17] P. M. White and C. W. Rice, "Tillage effects on microbial and carbon dynamics during plant residue decomposition," Soil Science Society of America Journal, vol. 73, no. 1, pp. 138-145, 2009.

[18] R. Derpsch, T. Friedrich, A. Kassam et al., "Current status of adoption of no-till farming in the world and some of its main benefits," International Journal of Agricultural and Biological Engineering, vol. 3, no. 1, pp. 1-25, 2010.

[19] D. Marandola, A. Belliggiano, L. Romagnoli, and C. Ievoli, "The spread of no-till in conservation agriculture systems in Italy: indications for rural development policy-making," Agricultural and Food Economics, vol. 7, no. 1, 2019.

[20] J. A. Silva, "Determination of fixed ammonium in soils," Retrospective Theses and Dissertations, vol. 2720, 1964.

[21] D. Hatton and W. F. Pickering, "Modified procedure for the determination of exchangeable ammonium ions in lake sediments," Chemical Speciation \& Bioavailability, vol. 2, no. 4, pp. 139-147, 1990.

[22] T. Hamamoto and Y. Uchida, "Sodium contents in dairy cow urine and soil aggregate sizes influence the amount of nitrogen lost from soil," Applied and Environmental Soil Science, vol. 2015, Article ID 275985, 10 pages, 2015.

[23] M. Oka and Y. Uchida, "Heavy metals in slag affect inorganic $\mathrm{N}$ dynamics and soil bacterial community structure and function," Environmental Pollution, vol. 243, pp. 713-722, 2018.

[24] J. G. Caporaso, C. L. Lauber, W. A. Walters et al., "Global patterns of $16 \mathrm{~S}$ rRNA diversity at a depth of millions of sequences per sample," Proceedings of the National Academy of Sciences, vol. 108, no. Supplement_1, p. 4516, 2011.

[25] R Core Team, R: A Language and Environment for Statistical Computing, R Foundation for Statistical Computing Vienna, Vienna, Austria, 2018, https://www.R-project.org.

[26] E. Martin and R. Hine, A Dictionary of Biology, Oxford University Press, Oxford, UK, 6th edition, 2008.

[27] E. Madejón, J. M. Murillo, F. Moreno et al., "Effect of longterm conservation tillage on soil biochemical properties in
Mediterranean Spanish areas," Soil and Tillage Research, vol. 105, no. 1, pp. 55-62, 2009.

[28] H. Liu, L. C. Carvalhais, V. Rincon-Florez et al., "One-time strategic tillage does not cause major impacts on soil microbial properties in a no-till Calcisol," Soil and Tillage Research, vol. 158, p. 91, 2016.

[29] R. Dick, "Soil enzyme activities as indicators of soil quality," in Defining Soil Quality for a Sustainable Environment, J. W. Doran, D. C. Coleman, D. F. Bezdicek, and B. A. Stewart, Eds., pp. 107-124, Soil Science Society of America, Madison, WI, USA, 1994.

[30] M. Alvear, A. Rosas, J. L. Rouanet, and F. Borie, "Effects of three soil tillage systems on some biological activities in an Ultisol from southern Chile," Soil and Tillage Research, vol. 82, no. 2, pp. 195-202, 2005.

[31] D. Pandey, M. Agrawal, and J. S. Bohra, "Effects of conventional tillage and no tillage permutations on extracellular soil enzyme activities and microbial biomass under rice cultivation," Soil and Tillage Research, vol. 136, p. 51, 2014.

[32] E. Kandeler, D. Tscherko, and H. Spiegel, "Long-term monitoring of microbial biomass, $\mathrm{N}$ mineralisation and enzyme activities of a Chernozem under different tillage management," Biology and Fertility of Soils, vol. 28, no. 4, pp. 343-351, 1999.

[33] R. Schmidt, K. Gravuer, A. V. Bossange, J. Mitchell, and K. Scow, "Long-term use of cover crops and no-till shift soil microbial community life strategies in agricultural soil," PLoS ONE, vol. 13, no. 2, Article ID e0192953, 2018.

[34] B. Breidenbach, J. Pump, and M. G. Dumont, "Microbial community structure in the rhizosphere of rice plants," Frontiers in Microbiology, vol. 6, p. 1537, 2016.

[35] E. V. Blagodatskaya and T.-H. Anderson, "Interactive effects of $\mathrm{pH}$ and substrate quality on the fungal-to-bacterial ratio and $\mathrm{qCO}_{2}$ of microbial communities in forest soils," Soil Biology and Biochemistry, vol. 30, no. 10-11, pp. 1269-1274, 1998.

[36] J. A. Klappenbach, J. M. Dunbar, and T. M. Schmidt, "rRNA operon copy number reflects ecological strategies of bacteria," Applied and Environmental Microbiology, vol. 66, no. 4, pp. 1328-1333, 2000.

[37] J. Rousk, P. C. Brookes, and E. Bååth, "The microbial PLFA composition as affected by $\mathrm{PH}$ in an arable soil," Soil Biology and Biochemistry, vol. 42, no. 3, pp. 516-520, 2010.

[38] F. T. De Vries, E. Hoffland, N. van Eekeren, L. Brussaard, and J. Bloem, "Fungal/bacterial ratios in grasslands with contrasting nitrogen management," Soil Biology and Biochemistry, vol. 38, no. 8, pp. 2092-2103, 2006.

[39] M. Pagliai, N. Vignozzi, and S. Pellegrini, "Soil structure and the effect of management practices," Soil and Tillage Research, vol. 79, no. 2, pp. 131-143, 2004.

[40] J. Rui, J. Peng, and Y. Lu, "Succession of bacterial populations during plant residue decomposition in rice field soil," Applied and Environmental Microbiology, vol. 75, no. 14, pp. 48794886, 2009.

[41] Y. Kim and W. Liesack, "Differential assemblage of functional units in paddy soil microbiomes," PLoS ONE, vol. 10, no. 4, Article ID e0122221, 2015.

[42] Y. Takenouchi, K. Iwasaki, and J. Murase, "Response of the protistan community of a rice field soil to different oxygen tensions," FEMS Microbiology Ecology, vol. 92, no. 7, p. 104, 2016.

[43] J. Meng, J. Xu, D. Qin et al., "Genetic and functional properties of uncultivated MCG archaea assessed by metagenome and gene expression analyses," The ISME Journal, vol. 8, no. 3, pp. 650-659, 2014. 
[44] C. S. Lazar, B. J. Baker, K. Seitz et al., "Genomic evidence for distinct carbon substrate preferences and ecological niches of Bathyarchaeota in estuarine sediments," Environmental Microbiology, vol. 18, no. 4, p. 1200, 2016.

[45] V. Acosta-Martínez, M. M. Mikha, and M. F. Vigil, "Microbial communities and enzyme activities in soils under alternative crop rotations compared to wheat-fallow for the central great plains," Applied Soil Ecology, vol. 37, no. 1-2, pp. 41-52, 2007.

[46] W. R. Cookson, D. V. Murphy, and M. M. Roper, "Characterizing the relationships between soil organic matter components and microbial function and composition along a tillage disturbance gradient," Soil Biology and Biochemistry, vol. 40 , no. 3 , p. 763,2008 .

[47] L. G. d. O. Denardin, F. d. C. Carmona, M. G. Veloso et al., "No-tillage increases irrigated rice yield through soil quality improvement along time," Soil and Tillage Research, vol. 186, pp. 64-69, 2019.

[48] T. A. Spedding, C. Hamel, G. R. Mehuys, and C. A. Madramootoo, "Soil microbial dynamics in maizegrowing soil under different tillage and residue management systems," Soil Biology and Biochemistry, vol. 36, no. 3, p. 499, 2004.

[49] B. L. Helgason, F. L. Walley, and J. J. Germida, "Long-term no-till management affects microbial biomass but not community composition in Canadian Prairie agroecosytems," Soil Biology and Biochemistry, vol. 42, no. 12, pp. 2192-2202, 2010.

[50] M. Pittol, E. Scully, D. Miller, L. Durso, L. Mariana Fiuza, and V. H. Valiati, "Bacterial community of the rice floodwater using cultivation-independent approaches," International Journal of Microbiology, vol. 2018, Article ID 6280484, 13 pages, 2018.

[51] F. J. Arriaga, J. Guzman, and B. Lowery, "Conventional agricultural production systems and soil functions," in Soil Health and Intensification of Agroecosytems, M. M. Al-Kaisim and B. Lowery, Eds., pp. 109-125, Academic Press, Cambridge, UK, 2017.

[52] K. Zhalnina, R. Dias, P. D. de Quadros et al., "Soil pH determines microbial diversity and composition in the park grass experiment," Microbial Ecology, vol. 69, no. 2, pp. 395-406, 2015. 